\title{
Refractory Nasal Cavity and Paranasal Sinus Squamous Cell Carcinoma
}

National Cancer Institute

\section{Source}

National Cancer Institute. Refractory Nasal Cavity and Paranasal Sinus Squamous Cell

Carcinoma. NCl Thesaurus. Code C148401.

Nasal cavity and paranasal sinus squamous cell carcinoma that does not respond to treatment. 